\title{
Effect of a Novel Water-Soluble Vitamin E Derivative, 2-( $\alpha$-D-Glucopyranosyl)methyl-2,5,7,8-tetramethylchroman- 6-ol, on Dextran Sulfate Sodium-Induced Colitis in Mice
}

\author{
Yuji NaIto, ${ }^{1, *}$ Tomohisa TAKagi,${ }^{1}$ Kiichi Matsuyama, ${ }^{1}$ Nobuaki Yagi, ${ }^{1}$ \\ Norimasa YoshIDA, ${ }^{1}$ Hironobu MURASE, ${ }^{2}$ and Toshikazu YosHIKAWA ${ }^{1}$ \\ ${ }^{I}$ First Department of Medicine, Kyoto Prefectural University of Medicine, Kamigyo-ku, \\ Kyoto 602-8566, Japan \\ ${ }^{2}$ CCI Corporation, Gifu 501-3923, Japan
}

(Received September 17, 2001)

\begin{abstract}
Summary Oxygen radical-mediated lipid peroxidation is involved in the tissue injury of inflammatory bowel disease. The present study investigated the effects of a novel water-soluble vitamin $\mathrm{E}$ derivative, 2-( $\alpha$-D-glucopyranosyl)methyl-2,5,7,8-tetramethylchroman-6-ol (TMG), on dextran sulfate sodium-induced colonic inflammation in mice. Acute colitis was induced in female mice by giving $8 \%$ dextran sulfate sodium orally in drinking water for 7 days. Animals were randomized to different concentrations of TMG $(1,10$, and 100 $\mathrm{mg} / \mathrm{kg}$ ) or physiologic saline (vehicle) by daily intraperitoneal injection. After 7 days of dextran sulfate sodium administration, mice had severe colonic inflammation characterized by significant decreases in total colon length, increases in luminal hemoglobin content and colonic myeloperoxidase activity. TMG at doses of 10 and $100 \mathrm{mg} / \mathrm{kg}$ reduced colonic injury and inflammation. The contents of thiobarbituric acid-reactive substances were significantly increased by dextran sulfate sodium administration, and this increase was reduced by TMG. These results indicate that the protective effect of TMG against colonic injury induced by dextran sulfate sodium may result, in part, from its inhibitory action toward lipid peroxidation, as well as from reduced neutrophil recruitment into the inflammatory site.
\end{abstract}

Key Words: colitis, dextran sulfate sodium, lipid peroxidation, mice, vitamin E analogue

We have proposed the hypothesis that lipid peroxidation mediated by oxygen radicals plays an important role in the pathogenesis of various gastrointestinal diseases [1-5]. Lipid peroxidation is believed to be an important cause of damage to cell membranes;

*To whom correspondence should be addressed. Fax: +81-75-252-3721. E-mail: ynaito@koto. kpu-m.ac.jp 
polyunsaturated fatty acids of cell membranes are degraded by lipid peroxidation with consequent disruption of membrane integrity [6,7]. Two lines of evidence support our hypothesis: (1) lipid peroxides significantly accumulate in the gastrointestinal mucosa during development of mucosal injury or inflammation, and (2) pretreatment with superoxide dismutase (SOD, a superoxide scavenger) or a hydroxyl radical scavenger greatly attenuates these injuries, as well as inhibiting the increase in lipid peroxides.

It has also been proposed that oxygen radical-mediated lipid peroxidation is involved in the development of tissue injury in Crohn's disease and ulcerative colitis [8-10], as well as experimental colitis in animal models [4]. Several animal models of human inflammatory bowel disease have been studied. In normal animals, a chronic granulomatous transmural colitis resembling Crohn's disease can be induced by application of trinitrobenzenesulfonylchloride (TNBS) to the colon; colitis induced by dextran sulfate sodium (DSS) is characterized by ulceration, epithelial damage, and mucosal inflammation resembling ulcerative colitis [11]. Tamai et al. [12] have reported a new model of colitis in rats in which the colon level of lipid peroxides was significantly increased by administration of $2,2^{\prime}$-azobis(2-amidinopropane)dihydrochloride (AAPH).

We have also shown in a model of TNBS-induced colitis that lipid peroxides are increased significantly in the colonic mucosa [4], and treatment with SOD improves the colitis score [13]. Several studies on human inflammatory bowel disease confirm that oxidative stress is created by overproduction of reactive oxygen species or by the decrease in plasma concentrations of antioxidants, including vitamins C and E [9, 14-16]. Aghdassi and Allard [10] recently measured breath pentane output, a marker of lipid peroxidation, in patients with Crohn's disease and found a higher level of breath pentane output when compared with healthy controls. These reports suggest that inhibition of lipid peroxidation or scavenging of oxygen radicals represents valuable preventive and therapeutic strategies for inflammatory bowel disease.

Vitamin E is a lipid-soluble antioxidant which protects membrane lipids from peroxidation $[17,18]$ and scavenges singlet oxygen $[19,20]$ and superoxide anion radical $[21$, 22]. Therefore, vitamin $E$ or its derivatives may be expected to have particular applications to patients suffering from diseases associated with oxygen radical-mediated lipid peroxidation. 2-( $\alpha$-D-Glucopyranosyl)methyl-2,5,7,8-tetramethylchroman-6-ol (TMG) is a novel synthetic vitamin $E$ derivative with excellent antioxidant activity equal to $\alpha$-tocopherol or ascorbic acid [23]. TMG has excellent water solubility due to replacement of the long phytyl side chain of $\alpha$-tocopherol by a glucosyl group. Our objective was to investigate changes in lipid peroxides at colonic inflammatory sites and the effect of TMG on DSS-induced colitis in mice.

\section{MATERIALS AND METHODS}

Chemicals. All chemicals were prepared immediately before use. TMG was a gift from CCI Pharmacy Co., Ltd. (Gifu, Japan). Thiobarbituric acid (TBA) and 3,3',5,5'tetramethylbenzidine were obtained from Wako Pure Chemical Industries, Ltd. (Osaka, Japan). 1,1,3,3-Tetramethoxy propane was obtained from Tokyo Kasei (Tokyo, Japan). 
All other chemicals used were of reagent grade.

Animals. Nine-week-old female BALB/c mice weighing 18 to $20 \mathrm{~g}$ were obtained from Keari Co., Ltd. (Osaka, Japan). Mice were housed in our animal quarters prior to experiments, and were maintained at 18 to $24^{\circ} \mathrm{C}$ with a 12 -h light/dark cycle. They were fed a standard diet (Oriental Yeast, Tokyo, Japan) and water ad libitum. Mice were anesthetized with urethane $(1 \mathrm{mg} / \mathrm{kg}$, i.p.) before they were killed by exsanguination from the abdominal aorta and colons were removed.

Induction of colitis and design of treatment. Acute colitis was induced by giving $8 \%$ DSS (molecular weight 8,000; lot no. DS-605; Seikagaku, Tokyo, Japan) orally in drinking water for 7 days according to our previous report [24, 25]. TMG was dissolved in physiologic saline. Mice were randomized into groups receiving different concentrations of TMG (or only the physiological saline vehicle) by intraperitoneal injection for 7 days. Mice were killed on day 7 , and colons were removed for histological examination and biochemical assay.

Evaluation of colonic inflammation. The grade of colonic inflammation was evaluated by the body weight, total colon length, and luminal hemoglobin. Colonic bleeding was quantified indirectly as hemoglobin concentration in luminal lavage fluid using the kit manufacturer's protocol (Wako). For histologic evaluation, formalin fixed tissues were stained with hematoxylin and eosin and evaluated microscopically by a pathologist unaware of the experimental conditions for any given specimen.

Measurements of TBA-reactive substances and MPO activity. As an index of lipid peroxidation, the concentration of thiobarbituric acid-reactive substances was measured in colonic mucosa using the method of Ohkawa et al. [26]. Colonic mucosa was scraped from the deeper layers using two glass slides and homogenized with $1.5 \mathrm{ml}$ of $10 \mathrm{~mm}$ potassium phosphate buffer ( $\mathrm{pH} 7.8$ ) containing $30 \mathrm{mM} \mathrm{KCl}$ in a Teflon Potter-Elvehjem homogenizer. Thiobarbituric acid-reactive substances in mucosal homogenates were expressed as nanomoles of malondialdehyde per milligram of protein using 1,1,3,3-tetramethoxypropane as a standard. Total protein in tissue homogenates was measured by the method of Lowry et al. [27].

As an index of neutrophil accumulation, tissue-associated myeloperoxidase activity was determined by a modification of the method of Grisham et al. [28]. Two milliliters of mucosal homogenate were centrifuged at $20,000 \times g$ for $15 \mathrm{~min}$ at $4^{\circ} \mathrm{C}$ to pellet insoluble cellular debris. The pellet then was rehomogenized in an equivalent volume of $0.05 \mathrm{M}$ potassium phosphate buffer ( $\mathrm{pH} 5.4$ ) containing $0.5 \%$ hexadecyltrimethylammonium bromide. Samples were centrifuged at $20,000 \times g$ for $15 \mathrm{~min}$ at $4^{\circ} \mathrm{C}$, and supernatants were saved. Myeloperoxidase activity was assessed by measuring $\mathrm{H}_{2} \mathrm{O}_{2}$-dependent oxidation of $3,3^{\prime}, 5,5^{\prime}$-tetramethylbenzidine. One unit of enzyme activity was defined as the amount of myeloperoxidase that caused a change in absorbance of $1.0 / \mathrm{min}$ at $655 \mathrm{~nm}$ and $25^{\circ} \mathrm{C}$.

Statistics. The results are presented as the mean \pm SEM. Data were compared by one-way analysis of variance. Differences were considered significant if the $p$ value was less than 0.05 based on Dunnett's multiple comparison test. All analyses were performed using Stat View 5.0-J program (Abacus Concepts Inc., Berkeley, CA) with a Macintosh computer.

Vol. 31, 2002 
Ethical consideration. Maintenance of animals and experimental procedures were carried out in accordance with the US National Institutes of Health guidelines for use of experimental animals. All experiments were approved by the Kyoto Prefectural University of Medicine Animal Care Committee (Kyoto, Japan).

\section{RESULTS}

\section{Effects of TMG on DSS-Induced Colitis in Mice}

Mice exposed to $8 \%$ DSS developed symptoms of acute colitis, with diarrhea being observed first, followed by rectal bleeding and severe body weight loss. The decreases in body weight and total colon length were significantly reversed by treatment with TMG at a dose of $100 \mathrm{mg} / \mathrm{kg}$ (Table 1). Lavage hemoglobin concentrations were significantly elevated by approximately 8-fold in the DSS only administration group. This response was abolished by TMG treatment at doses of 10 and $100 \mathrm{mg} / \mathrm{kg}$ (Table 1).

The protective effect of TMG was also confirmed by histology. Figure 1 shows typical histological features in the TMG $(10 \mathrm{mg} / \mathrm{kg})$-treated group and DSS only administration group. Administration of $8 \%$ DSS for 7 days resulted in large areas of epithelial crypt loss, a predominantly neutrophilic infiltration throughout the mucosa, ulceration, and mucosal bleeding. In contrast, treatment with TMG produced smaller erosions with few neutrophils.

\section{Effects of TMG on TBA-Reactive Substances in Colonic Mucosa}

TBA-reactive substances in the colonic mucosa increased significantly from a basal mean concentration of $3.407 \pm 0.193 \mathrm{nmol} / \mathrm{mg}$ protein to $6.694 \pm 1.216 \mathrm{nmol} / \mathrm{mg}$ protein on the 7 th day after DSS administration (Fig. 2). The increase in TBA-reactive substances was significantly inhibited by treatment with TMG at doses of 10 and $100 \mathrm{mg} / \mathrm{kg}$ (Fig. 2).

Table 1. Effects of the vitamin E analogue TMG on body weight, total colon length, and intraluminal hemoglobin in dextran sulfate sodium-induced colitis in mice.

\begin{tabular}{lccc}
\hline \multicolumn{1}{c}{ Group } & $\begin{array}{c}\text { Weight gain } \\
\text { (g/7 days })\end{array}$ & $\begin{array}{c}\text { Colon length } \\
(\mathrm{cm})\end{array}$ & $\begin{array}{c}\text { Luminal hemoglobin } \\
(\mathrm{mg} / \mathrm{cm})\end{array}$ \\
\hline No colitis & $1.18 \pm 0.44$ & $10.98 \pm 0.24$ & $0.80 \pm 0.19$ \\
DSS only & $-2.58 \pm 0.25^{\#}$ & $8.98 \pm 0.08^{\#}$ & $6.29 \pm 1.12^{\#}$ \\
TMG plus DSS & & & \\
$1 \mathrm{mg} / \mathrm{kg}$ & $-1.94 \pm 0.25$ & $9.26 \pm 0.28$ & $5.88 \pm 2.26$ \\
$10 \mathrm{mg} / \mathrm{kg}$ & $-1.62 \pm 0.52$ & $10.14 \pm 0.12^{* *}$ & $2.06 \pm 0.48^{*}$ \\
$100 \mathrm{mg} / \mathrm{kg}$ & $-1.38 \pm 0.29^{*}$ & $10.42 \pm 0.24^{* * *}$ & $1.96 \pm 0.50^{*}$ \\
\hline
\end{tabular}

Acute colitis was induced with $8 \%$ dextran sulfate sodium (DSS) solution orally in drinking water for 7 days. The agent TMG was dissolved in physiological saline and given to mice by intraperitoneal injection once a day for 7 days at doses of 1,10 , and $100 \mathrm{mg} / \mathrm{kg} / \mathrm{day}$. Each value indicates the mean \pm SE for 6 to 8 mice. ${ }^{*} p<0.001$ compared with mice without colitis. ${ }^{*} p<0.05$, $* * p<0.01$, and $* * * p<0.001$ compared with mice receiving only DSS. TMG: 2 - $(\alpha-D$-glucopyranosyl)methyl-2,5,7,8-tetramethylchroman-6-ol. 


\section{Effects of TMG on MPO Activity in Colonic Mucosa}

Neutrophil accumulation was also evaluated by measurement of MPO activity in the colonic mucosal homogenates. Tissue-associated MPO activity in the colonic mucosa increased significantly from a basal mean concentration of $0.43 \pm 0.06 \mathrm{mU} / \mathrm{mg}$ protein to $3.92 \pm 1.09 \mathrm{mU} / \mathrm{mg}$ protein on the 7th day after DSS administration (Fig. 3). The increase

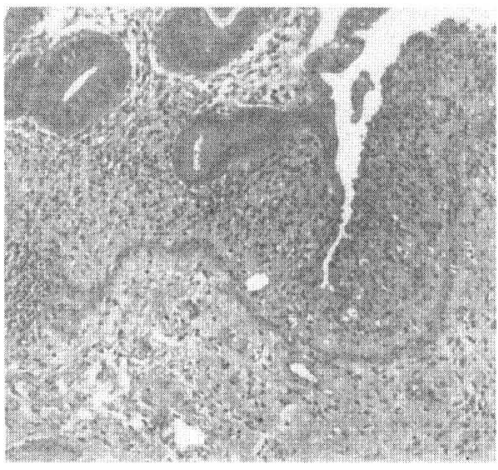

(A)

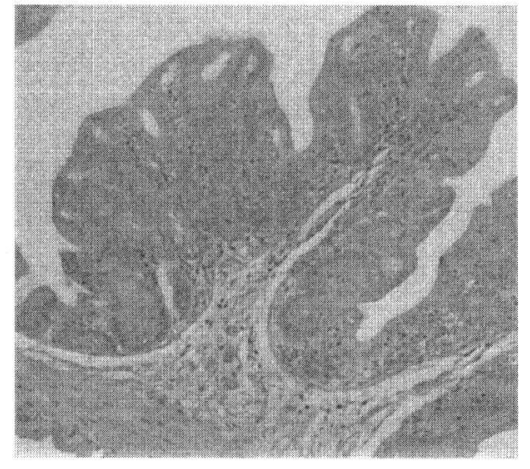

(B)

Fig. 1. Hematoxylin and eosin staining of the colon in dextran sulfate sodium (DSS)-treated (A) and DSS plus TMG-treated mice (B). The colon shows loss and shortening of crypts, mucosal erosions, inflammatory cell infiltration, and goblet cell depletion in DSS-treated mice. In contrast, treatment with TMG at a dose of $10 \mathrm{mg} / \mathrm{kg}$ produces smaller erosions with few inflammatory cells. TMG: 2-( $\alpha$-D-glucopyranosyl)methyl-2,5,7,8-tetramethylchroman-6-ol.

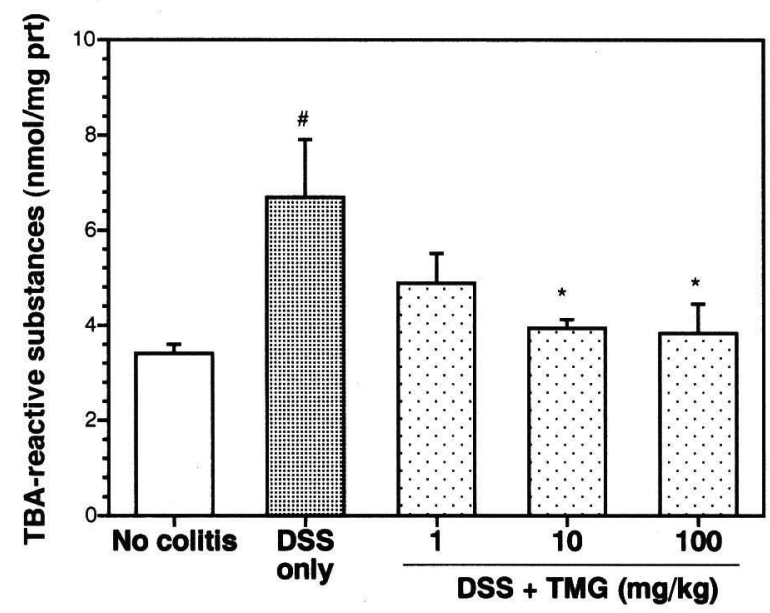

Fig. 2. Effect of TMG on the increase in lipid peroxide concentration in the colonic mucosa of mice treated with $8 \%$ dextran sulfate sodium (DSS). Each value indicates the mean \pm SE of 6 to 8 mice. ${ }^{*} p<0.01$ compared with mice without colitis. ${ }^{*} p<0.01$ compared with mice receiving only DSS. TMG: 2-( $\alpha$-D-glucopyranosyl)methyl-2,5,7,8-tetramethylchroman-6-ol. 


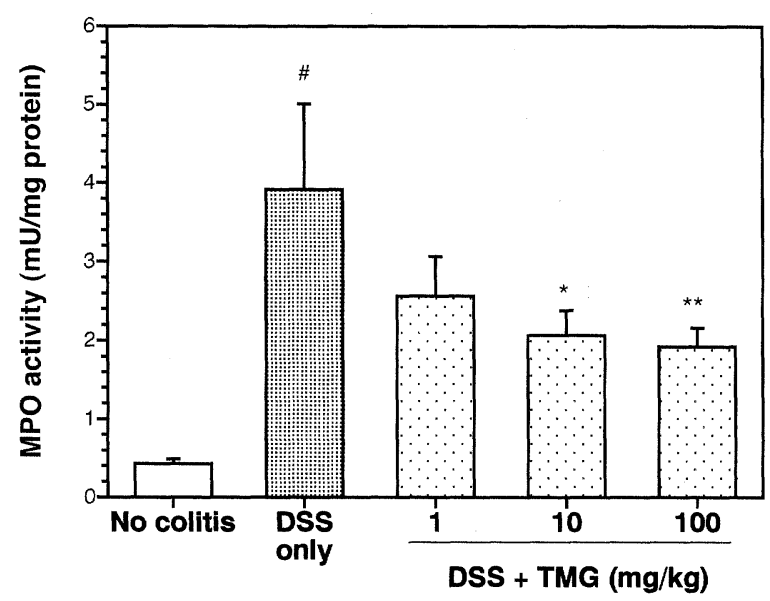

Fig. 3. Effect of TMG on neutrophil accumulation in the colonic mucosa of mice treated with $8 \%$ dextran sulfate sodium (DSS). Each value indicates the mean \pm SE for 6 to 8 mice. ${ }^{*} p<0.001$ compared with mice without colitis. ${ }^{*} p<0.05$ and $* * p<0.01$ compared with mice receiving only DSS. TMG: 2-( $\alpha$-D-glucopyranosyl)methyl-2,5,7,8-tetramethylchroman-6-ol.

in MPO activity in colonic mucosa after DSS administration was significantly inhibited by treatment with TMG at doses of 10 and $100 \mathrm{mg} / \mathrm{kg}$.

\section{DISCUSSION}

The present study demonstrates for the first time that TMG, a novel vitamin E analogue, attenuates DSS-induced colonic injury and inflammation in mice. In our study, intestinal injury was assessed by a variety of methods including body weight, length of the colon, luminal content of hemoglobin, granulocytic infiltration, and histology. In each assessment, TMG treatment significantly inhibited colonic injury. An important observation of the present study is that TBA-reactive substances, an index of lipid peroxidation, are significantly increased in the colonic mucosa after DSS administration; this increase is significantly inhibited by treatment with TMG at doses of 10 and $100 \mathrm{mg} / \mathrm{kg}$. Much recent attention has been focused on the role of lipid peroxidation mediated by oxygen free radicals in precipitating gastrointestinal mucosal injuries induced by several kinds of stress $[1,29]$ or ischemia-reperfusion [30], and by inflammation $[4,31]$ in animal models. Polyunsaturated fatty acids of the cellular membranes are degraded by lipid peroxidation with subsequent disruption of membrane integrity, suggesting that lipid peroxidation mediated by oxygen radicals is an important cause of damage and destruction of cell membranes $[32,33]$. Our data support a previous finding in which colonic TBA-reactive substances were markedly reduced in TNBS-colitis mice treated with TMG [34], suggesting that induction of lipid peroxidation is an early and critical event in this experimental model of inflammatory bowel disease.

Recent reports have hypothesized that neutrophil-mediated inflammation is involved in the development of DSS-induced colonic mucosal injury. Three lines of evidence sup- 
port this hypothesis: 1) colonic mucosal endothelial intercellular adhesion molecule 1 (ICAM-1) expression is enhanced at an early stage in the inflammatory cascade of DSSinduced colitis [35], 2) selective depletion of neutrophils by monoclonal antibody RP-3 suppresses colitis in rats [36], and 3) immunoneutralization of ICAM-1 on endothelial cells significantly attenuated colonic mucosal injury and neutrophil accumulation [37]. The present study has shown that MPO activity, an index of tissue-associated neutrophil accumulation, significantly increases in colonic mucosa after DSS administration, and this increase is significantly inhibited by treatment with TMG. These results indicate that the inhibition of neutrophil accumulation by TMG may be one of the protective factors decreasing DSS-induced colonic mucosal injury.

Vitamin $\mathrm{E}$ is well known as a lipid-soluble vitamin and radical-scavenging antioxidant. However, vitamin $\mathrm{E}$ is lipophilic, and to be absorbed into tissue, oral vitamin $\mathrm{E}$ must be absorbed at the microvilli of the small intestine independently or by interaction with chylomicrons, then carried to the liver by the lymphatics and distributed among lipoproteins before transport to other organs [38]. TMG is a synthetic vitamin E derivative with a chromanol ring, responsible for radical-scavenging activity, in common with $\alpha$-tocopherol, a major constituent of vitamin E. TMG acquires its water-solubility $(>1 \mathrm{~g} / \mathrm{ml})$ by replacement of the long phytyl side chain of $\alpha$-tocopherol with a glucosyl group [23]. The high water-solubility of TMG enables it to be carried to the organs and supplied to tissue rapidly. TMG also shows an excellent antioxidant activity equal to $\alpha$-tocopherol or ascorbic acid [23]. TMG is presumed to be located within the membrane surface where it can scavenge both chain-initiating radicals and chain-propagating radicals in the lipid phase; TMG also is an efficient antioxidant against radicals generated in the aqueous phase [39]. Therefore, TMG has many advantages as a therapeutic modality in inflammatory bowel disease in comparison with $\alpha$-tocopherol.

We speculate that the pharmacologic effects of TMG may be dependent upon a combination of: (1) an inhibitory action towards lipid peroxidation and (2) reduced neutrophil recruitment into inflammatory sites, which may represent an important additional mechanism for its observed anti-inflammatory action. TMG must be considered as a likely therapeutic agent for inflammatory bowel disease.

\section{REFERENCES}

1. Yoshikawa, T., Miyagawa, H., Yoshida, N., Sugino, S., and Kondo, M. (1986): Increase in lipid peroxidation in rat gastric mucosal lesions induced by water-immersion restraint stress. J. Clin. Biochem. Nutr., 1, 271-277.

2. Yoshikawa, T., Naito, Y., Kishi, A., Tomii, T., Kaneko, T., Iinuma, S., Ichikawa, H., Yasuda, M., Takahashi, S., and Kondo, M. (1993): Role of active oxygen, lipid peroxidation, and antioxidants in the pathogenesis of gastric mucosal injury induced by indomethacin in rats. Gut, 34, 732-737.

3. Yoshikawa, T., Naito, Y., and Kondo, M. (1993): Antioxidant therapy in digestive diseases. J. Nutr. Sci. Vitaminol., 39, S35-S41.

4. Yoshikawa, T., Yamaguchi, T., Yoshida, N., Yamamoto, H., Kitazumi, S., Takahashi, S., Naito, Y., and Kondo, M. (1997): Effect of Z-103 on TNB-induced colitis in rats. Digestion, 58, 464-468.

5. Yoshikawa, T., Naito, Y., Yoshida, N., and Kondo, M. (1998): Nitric oxide, adhesion molecules, and tissue injury, in Biological Oxidants and Antioxidants: Molecular Mechanism and Health Effects,

Vol. 31, 2002 
ed. by Packer, L., and Ong, A.S.H., AOCS Press, Champaign, IL, pp. 36-41.

6. Niki, E. (1987): Antioxidants in relation to lipid peroxidation. Chem. Phys. Lipids, 44, 227-253.

7. Fridovich, I. (1978): The biology of oxygen radicals. Science, 201, 875-880.

8. Pelli, M.A., Trovarelli, G., Capodicasa, E., De, M.G., and Bassotti, G. (1999): Breath alkanes determination in ulcerative colitis and Crohn's disease. Dis. Colon Rectum, 42, 71-76.

9. Ramakrishna, B.S., Varghese, R., Jayakumar, S., Mathan, M., and Balasubramanian, K.A. (1997): Circulating antioxidants in ulcerative colitis and their relationship to disease severity and activity. $J$. Gastroenterol. Hepatol., 12, 490-494.

10. Aghdassi, E., and Allard, J.P. (2000): Breath alkanes as a marker of oxidative stress in different clinical conditions. Free Radic. Biol. Med., 28, 880-886.

11. Okayasu, I., Hatakeyama, S., Yamada, M., Ohkusa, T., Inagaki, Y., and Nakaya, R. (1990): A novel method in the induction of reliable experimental acute and chronic ulcerative colitis in mice. Gastroenterology, 98, 694-702.

12. Tamai, H., Levin, S., and Gagnella, T.S. (1992): Induction of colitis in rats by 2 -2'-azobis(2-amidinopropane)dihydrochloride. J. Immunol. Methods, 76, 69-81.

13. Yoshida, N., Yamaguchi, T., Kitazumi, S., Takahashi, S., Naito, Y., Yoshikawa, T., and Kondo, M. (1997): Role of PMN and active oxygen species in the pathogenesis of TNB-colitis in rats, in Cytokines, Cholera, and the Gut, ed. by Keusch, G.T., and Kawakami, M., Ohmsha, Tokyo, pp. 131-135.

14. Bousvaros, A., Zurakowski, D., Duggan, C., Law, T., Rifai, N., Goldberg, N.E., and Leichtner, A.M. (1998): Vitamins A and E serum levels in children and young adults with inflammatory bowel disease: Effect of disease activity. J. Pediatr. Gastroenterol. Nutr., 26, 129-135.

15. Geerling, B.J., Badart, S.A., Stockbrugger, R.W., and Brummer, R.J. (1998): Comprehensive nutritional status in patients with long-standing Crohn disease currently in remission [see comments]. Am. J. Clin. Nutr., 67, 919-926.

16. Geerling, B.J., v Houwelingen, A.C., Badart Smook, A., Stockbrugger, R.W., and Brummer, R.J. (1999): The relation between antioxidant status and alterations in fatty acid profile in patients with Crohn disease and controls. Scand. J. Gastroenterol., 34, 1108-1116.

17. Burton, G.W., Joyce, A., and Ingold, K.U. (1982): First proof that vitamin E is major lipid-soluble, chain-breaking antioxidant in human blood plasma. Lancet, 8293, 327.

18. Niki, E., Yamamoto, Y., Takahashi, M., Komuro, E., and Miyama, Y. (1989): Inhibition of oxidation of biomembranes by tocopherol. Ann. N.Y. Acad. Sci., 570, 23-31.

19. Yamauchi, R., and Matsushita, S. (1977): Quenching effect of tocopherols on the methyl linoleate photooxidation and their oxidation products. Agric. Biol. Chem., 41, 1425-1430.

20. Mukai, K., Daifuku, K., Okabe, K., Tanigaki, T., and Inoue, K. (1991): Structure-activity relationship in the quenching reaction of singlet oxygen by tocopherol (vitamin E) derivatives and related phenols. Finding of linear correlation between the rates of quenching of singlet oxygen and scavenging of peroxyl and phenoxyl radicals in solution. J. Org. Chem., 56, 4188-4192.

21. Nishikimi, M., Yamada, H., and Yagi, K. (1980): Oxidation by superoxide of tocopherols dispersed in aqueous media with deoxycholate. Biochim. Biophys. Acta, 627, 101-108.

22. Fukuzawa, K., and Gebicki, J.M. (1983): Oxidation of alpha-tocopherol in micelles and liposomes by the hydroxyl, perhydroxyl, and superoxide free radicals. Arch. Biochem. Biophys., 226, 242251.

23. Murase, H., Yamauchi, R., Kato, K., Kunieda, T., and Terao, J. (1997): Synthesis of a novel vitamin E derivative, 2-(alpha-D-glucopyranosyl)methyl-2,5,7,8-tetramethylchroman-6-ol, by alpha-glucosidase-catalyzed transglycosylation. Lipids, 32, 73-78.

24. Naito, Y., Takagi, T., Ishikawa, T., Handa, O., Matsumoto, N., Yagi, N., Matsuyama, K., Yoshida, N., and Yoshikawa, T. (2001): The inducible nitric oxide inhibitor ONO-1714 blunts dextran sulfate sodium colitis in mice. Eur. J. Pharmacol., 412, 91-99.

25. Naito, Y., Takagi, T., Handa, O., Ishikawa, T., Matsumoto, N., Yagi, N., Matsuyama, K., Nakagawa, S., Yamaguchi, T., Yoshida, N., and Yoshikawa, T. (2001): Role of superoxide and lipid peroxidation in the pathogenesis of dextran sulfate sodium-colitis in mice. ITE Letters, 2, 712-716.

26. Ohkawa, H., Ohishi, N., and Yagi, K. (1986): Assay for lipid peroxides for animal tissues by thiobarbituric acid reaction. Anal. Biochem., 95, 351-358.

27. Lowry, O.H., Rosebrough, N.J., Farr, A.L., and Randall, R.J. (1951): Protein measurement with the 
folin phenol reagent. J. Biol. Chem., 193, 265-275.

28. Grisham, M.B., Hernandez, L.A., and Granger, D.N. (1986): Xanthine oxidase and neutrophil infiltration in intestinal ischemia. Am. J. Physiol., 252, G567-G574.

29. Yoshikawa, T., Yoshida, N., Miyagawa, H., Takemura, T., Tanigawa, T., Sugino, S., and Kondo, M. (1987): Role of lipid peroxidation in gastric mucosal lesions induced by burn shock in rats. J. Clin. Biochem. Nutr., 2, 163-170.

30. Yoshikawa, T., Ueda, S., Naito, Y., Takahashi, S., Oyamada, H., Morita, Y., Yoneta, T., and Kondo, M. (1989): Role of oxygen-derived free radicals in gastric mucosal injury induced by ischemia or ischemia-reperfusion in rats. Free Radic. Res. Commun., 7, 285-291.

31. Iinuma, S., Yoshikawa, T., Yoshida, N., Naito, Y., and Kondo, M. (1998): Role of active oxygen species and lipid peroxidation in mepirizole-induced duodenal ulcers in rats. Dig. Dis. Sci., 43, 16571664.

32. Niki, E., and Komuro, E. (1988): Inhibition of peroxidation of membranes. Basic Life Sci., 49, 561-566.

33. Niki, E., Noguchi, N., and Gotoh, N. (1993): Dynamics of lipid peroxidation and its inhibition by antioxidants. Biochem. Soc. Trans., 21, 313-317.

34. Yoshida, N., Yoshikawa, T., Yamaguchi, T., Naito, Y., Tanigawa, T., Murase, H., and Kondo, M. (1999): A novel water-soluble vitamin $\mathrm{E}$ derivative protects against experimental colitis in rats. Antioxid. Redox Signaling, 1, 555-562.

35. Breider, M.A., Eppinger, M., and Gough, A. (1997): Intercellular adhesion molecule-1 expression in dextran sodium sulfate-induced colitis in rats. Vet. Pathol., 34, 598-604.

36. Natsui, M., Kawasaki, K., Takizawa, H., Hayashi, S., Matsuda, Y., Sugimura, K., Seki, K., Narisawa, R., Sendo, F., and Asakura, H. (1997): Selective depletion of neutrophils by a monoclonal antibody, RP-3, suppresses dextran sulphate sodium-induced colitis in rats. J. Gastroenterol. Hepatol., 12, 801-808.

37. Taniguchi, T., Tsukada, H., Nakamura, H., Kodama, M., Fukuda, K., Saito, T., Miyasaka, M., and Seino, Y. (1998): Effects of the anti-ICAM-1 monoclonal antibody on dextran sodium sulphateinduced colitis in rats. J. Gastroenterol. Hepatol., 13, 945-949.

38. Drevon, C.A. (1993): Absorption, metabolism, and excretion of vitamin E, in Vitamin E-Its Usefulness in Health and in Curing Diseases, ed. by Mino, M., Nakamura, H., Diplock, A.T., and Kayden, H.J., S. Karger, Basel, pp. 65-83.

39. Murase, H., Moon, J.H., Yamauchi, R., Kato, K., Kunieda, T., Yoshikawa, T., and Terao, J. (1998): Antioxidant activity of a novel vitamin E derivative, 2-(alpha-D-glucopyranosyl)methyl-2,5,7,8tetramethylchroman-6-ol. Free Radic. Biol. Med., 24, 217-225. 